\title{
Evaluation of the Effect of Cumulative Cisplatin Dose in Locoregionally Advanced Nasopharyngeal Carcinoma Patients Receiving Intensity-Modulated Radiotherapy
}

Sheng-Chiao Lin

Kaohsiung Veterans General Hospital

Yu-Hsuan Lin

Kaohsiung Veterans General Hospital

Yaoh-Shiang Lin

Kaohsiung Veterans General Hospital

Bor-Hwang Kang

Kaohsiung Veterans General Hospital

Kuo-Ping Chang

Kaohsiung Veterans General Hospital

Ting-Shou Chang ( $\nabla$ aso0225@hotmail.com )

Kaohsiung Veterans General Hospital

\section{Research}

Keywords: Nasopharyngeal carcinoma, cumulative cisplatin dose, intensity-modulated radiotherapy

Posted Date: April 8th, 2020

DOI: https://doi.org/10.21203/rs.3.rs-21436/v1

License: (c) (i) This work is licensed under a Creative Commons Attribution 4.0 International License.

Read Full License 


\section{Abstract}

Background: In nasopharyngeal carcinoma (NPC), the cut-off value of cumulative cisplatin dose (CCD) associated with survival benefits remains controversial. This study aimed to determine a CCD cut-off value for favorable survival outcomes and to identify specific patient groups benefitting from higher CCDs.

Methods: We retrospectively reviewed the records of 161 patients (male-to-female ratio of 2.6:1.0) with NPC receiving concurrent chemoradiotherapy \pm adjuvant chemotherapy (AC) from February 2006 through September 2015 at our referral center. The CCD was calculated for each patient, and 3-year locoregionalfree survival (LRFS), distant-metastasis free survival (DMFS), disease-specific survival (DSS), and overall survival (OS) were analyzed using a multivariable Cox regression model.

Results: Stage N3 patients and stage IV patients had lower DMFS, DSS, and OS. A CCD $\geq 200 \mathrm{mg} / \mathrm{m} 2$ or AC was not associated with survival benefits. After adjusting for other factors, N3 status remained robustly correlated with DMFS $(p<0.001)$ and DSS $(p=0.001)$. In subgroup analyses, stage N3 patients treated with CCD $\geq 200 \mathrm{mg} / \mathrm{m} 2$ exhibited evident trends toward higher OS ( $p=0.119)$, DSS $(p=0.119)$, $\operatorname{DMFS}(p=0.201)$, and LRFS $(p=0.125)$ than patients treated with $\operatorname{CCD}<200 \mathrm{mg} / \mathrm{m} 2$.

Conclusions: A CCD $\geq 200 \mathrm{mg} / \mathrm{m} 2$ might result in better survival outcomes in stage N3 patients. Larger CCDs may be exclusively used in cases of regionally advanced disease to avoid rigorous toxicity.

\section{Background}

Nasopharyngeal carcinoma (NPC) is an endemic cancer in China, Indonesia, Vietnam, India, and Malaysia.[1] In some areas in China, the annual incidence of NPC is 26.95 cases per 100,000 people; the annual mortality was 14.28 cases per 100,000 people in 2013.[2] Owing to the anatomical positioning of the disease and the radiosensitive and chemosensitive nature of NPC, radiotherapy (RT) with or without chemotherapy (CT) has become a mainstream treatment. It yields 5-year disease-specific survival (DSS) rates as high as $94 \%$ and $84 \%$ for patients with stage I-II and stage III-IV disease, respectively.[3] The advancement of CT has significantly enhanced survival advantage, locoregional control, and distant control.[4,5] However, late toxicity and the rate of hearing impairments notably increased after the advent of $\mathrm{CT} .[3,6,7]$ Therefore, we have investigated whether specific groups of patients may benefit from higher cumulative cisplatin doses (CCDs) to achieve better survival outcomes and avoid adverse morbidity.

Higher CCDs have played a role in improving survival in patients with head and neck squamous cell carcinoma undergoing primary concurrent chemoradiotherapy (CCRT).[8] Beneficial survival outcomes have been obtained using CCD cut-offs above $200 \mathrm{mg} / \mathrm{m}^{2}$ in concurrent CT.[9, 10] In NPC, despite the fact that superior survival rates have been reported for CCDs $\geq 200 \mathrm{mg} / \mathrm{m}^{2},[5,11-14]$ cut-off points remain controversial. Ou et al.[15] reported significantly higher distant metastasis-free survival (DMFS) and overall survival (OS) rates with $C C D \geq 300 \mathrm{mg} / \mathrm{m}^{2}$ in concurrent $\mathrm{CT}$, especially for patients with $\mathrm{N} 2-3$ 
lesions. On the other hand, Peng et al.[16] reported significantly higher disease-free survival with CCD $\geq$ $240 \mathrm{mg} / \mathrm{m}^{2}$ in concurrent CT.

We aimed to determine a CCD cut-off value linked to favorable survival outcomes and, most importantly, determine the target group of patients benefitting from higher CCDs during CCRT.

\section{Methods}

\section{Ethical considerations}

This study was approved by the Institutional Review Board of Kaohsiung Veterans General Hospital, Taiwan (IRB: VGHKS17-CT5-17). The requirement for informed consent was waived because all identifying information was removed from the dataset prior to analysis.

\section{Study design}

We retrospectively reviewed the electronic medical records of patients with NPC undergoing primary CCRT and/or adjuvant chemotherapy (AC) at a tertiary medical center in Taiwan from February 2006 through September 2015. We excluded patients who had received prior RT or CT, who had aborted the RT, who did not have complete dosage records of $\mathrm{CT}$, and who had received concurrent or adjuvant injectable regimens other than cisplatin. We enrolled 161 patients in the study.

\section{Data collection}

Either the clinical stage or pathological tumor stage was recorded according to the seventh edition of the staging system from the American Joint Committee on Cancer. The CCD was only calculated the patients receiving concurrent cisplatin dosage.

\section{Radiotherapy, chemotherapy, and follow-up}

At our institute, patients with stage I-II NPC were treated by RT alone or CCRT. Patients with stage III-IVB lesions were treated with CCRT with or without induction/adjuvant CT. The total cumulative dose of radiation applied to the gross nasopharyngeal tumor ranged from 66-78 Gray (Gy). The clinical negative nodal regions were prophylactically covered by 50-56 Gy; 60-66 Gy were used for positive nodal areas. The regimens for $A C$ included cisplatin $\left(80 \mathrm{mg} / \mathrm{m}^{2}\right.$, on Day 1$)$ and fluorouracil $\left(1,000 \mathrm{mg} / \mathrm{m}^{2}, 96\right.$-hour continuous infusion from Days 2-5) administered every 3-4 weeks for $2-3$ cycles. The regimen for concurrent CT was $80-100 \mathrm{mg} / \mathrm{m}^{2}$ of cisplatin on Days 1,22 , and 43 or $30-40 \mathrm{mg} / \mathrm{m}^{2}$ of cisplatin every week for 6-8 cycles during the period of RT. Patients were instructed to receive regular follow-ups at our clinic every 3 months during the first 3 years following treatment. The follow-up frequency gradually decreased to every 6 months in the following 2 years and to once yearly after the sixth year.

\section{Clinical end points}


Clinical endpoints included 3-year OS, DSS, and any recurrence or distant metastasis. The OS was defined as the time elapsed between the diagnosis and the date of death from any cause; it was defined as three years if patient was still alive at the end of the study period. The DSS, locoregional-free survival (LRFS), and DMFS were otherwise calculated from the start of RT. Patients who were lost to follow-up within 3 years were censored at their last date of follow-up.

\section{Statistical analysis}

All of the statistical analyses were performed using SPSS ver. 22 (SPSS, Inc., Chicago, IL, USA). Pearson's chi-squared test or Fisher's exact test were used to explore the differences between categorical variables; the $t$-test was used for continuous variables. The OS, DSS, DMFS, and LRFS were generated according to the Kaplan and Meier methods. Differences between survival curves were compared using the log-rank test. The prognostic influence of factors during therapy was assessed using the Cox proportional hazards multivariate model after adjusting for other variables. Furthermore, subgroup analyses with log-rank test was used to evaluate the survival benefit for the stage N3 patients receiving CCD $\geq 200 \mathrm{mg} / \mathrm{m}^{2}$.

\section{Results}

Ultimately, 161 patients with NPC (mean age: $49.4 \pm 10.4$ years; 116 males [72\%], and 45 females [28\%]) were included in the analysis. The demographic characteristics of the cohort are summarized in Table 1. Among these patients, $60.2 \%$ were in stages T3-4 $(n=97)$ and $83.2 \%$ were in stages $\mathrm{N} 2-3(n=134)$. The mean CCD was $170.0 \pm 67.8 \mathrm{mg} / \mathrm{m}^{2}$. Eighty-six patients (53.4\%) cases received a CCD less than $200 \mathrm{mg} / \mathrm{m}^{2} ; 75$ patients $(46.6 \%)$ received a CCD of at least $200 \mathrm{mg} / \mathrm{m}^{2}$. In the group receiving a CCD $\geq$ $200 \mathrm{mg} / \mathrm{m}^{2}$, there was a predominance of males $(p=0.036)$ and a higher percentage of N3 $(p=0.032)$ and stage IV $(p=0.022)$ individuals. In total cohort, the 3-year LRFS, DMFS, DSS, and OS were $91.3 \%$, $90.2 \%, 87.3 \%$, and $83.6 \%$, respectively. The significant factors associated with a lower 3 -year DMFS according to the univariate analysis included a female gender $(p=0.036)$ and stage $11-2$ disease $(p=$ 0.035). Furthermore, stage N3 or stage IV disease was significantly associated with a reduced DMFS ( $p<$ 0.001 and $p=0.004$, respectively), DSS ( $p<0.001$ and $p=0.002$, respectively), and OS $(p=0.006$ and $p=$ 0.018 , respectively) (Table 2 ). 
Table 1

Patient characteristics

\begin{tabular}{|c|c|c|c|c|}
\hline & & Cumulative cispl & CRT & \\
\hline Variable & All & $\begin{array}{l}\text { Cisplatin dose }< \\
200 \mathrm{mg} / \mathrm{m}^{2}\end{array}$ & $\begin{array}{l}\text { Cisplatin dose } \geqq \\
200 \mathrm{mg} / \mathrm{m}^{2}\end{array}$ & $p$ \\
\hline Age & & $49.21 \pm 10.98$ & $49.64 \pm 9.76$ & 0.794 \\
\hline $\operatorname{Sex}(\%)$ & & & & 0.036 \\
\hline male & $116(72.0)$ & $56(65.1)$ & $60(80.0)$ & \\
\hline female & $45(28.0)$ & $30(34.9)$ & $15(20.0)$ & \\
\hline Smoke (\%) & & & & 0.107 \\
\hline No & 109(67.7) & 63(73.3) & $46(61.3)$ & \\
\hline Yes & $52(32.3)$ & $23(26.7)$ & 29(38.7) & \\
\hline CCIS (\%) & & & & 0.992 \\
\hline 0 & $131(81.4)$ & $70(81.4)$ & 61(81.3) & \\
\hline$\geqq 1$ & $30(18.6)$ & $16(18.6)$ & $14(18.7)$ & \\
\hline Histology type & & & & 0.232 \\
\hline NUC & $143(88.8)$ & $74(86.0)$ & $69(92.0)$ & \\
\hline NDC & $18(11.2)$ & $12(14.0)$ & $6(8.0)$ & \\
\hline T stage (\%) & & & & 0.527 \\
\hline $\mathrm{T} 1$ & $43(26.7)$ & $24(27.9)$ & 19(25.3) & \\
\hline $\mathrm{T} 2$ & $21(13.0)$ & $10(11.6)$ & $11(14.7)$ & \\
\hline T3 & $67(41.6)$ & $39(45.3)$ & $28(37.3)$ & \\
\hline $\mathrm{T} 4$ & $30(18.6)$ & $13(15.1)$ & $17(22.7)$ & \\
\hline $\mathrm{N}$ stage (\%) & & & & $0.032^{\star}$ \\
\hline NO & $8(5.0)$ & $5(5.8)$ & $3(4.0)$ & \\
\hline $\mathrm{N} 1$ & 19(11.8) & $11(12.8)$ & $8(10.7)$ & \\
\hline
\end{tabular}

CCIS, Charlson Comorbidity Index Score; NUC, nonkeratinizing undifferentiated carcinoma; NDC, nonkeratinizing differentiated carcinoma; CT, chemotherapy; CCRT, concurrent chemoradiotherapy

Values are numbers (percentage)

*Fisher's exact test 


\begin{tabular}{|c|c|c|c|c|}
\hline \multicolumn{5}{|c|}{ Cumulative cisplatin dose in CCRT } \\
\hline N2 & $113(70.2)$ & $65(75.6)$ & $48(64.0)$ & \\
\hline N3 & 21(13.0) & $5(5.8)$ & $16(21.3)$ & \\
\hline $\begin{array}{l}\text { AJCC Stage } \\
(\%)\end{array}$ & & & & 0.022 \\
\hline Stage 3 & $\begin{array}{l}113 \\
(70.2)\end{array}$ & $67(77.9)$ & $46(61.3)$ & \\
\hline Stage 4 & $48(29.8)$ & $19(22.1)$ & $29(38.7)$ & \\
\hline Adjuvant CT & & & & 0.009 \\
\hline No & $107(66.5)$ & $65(75.6)$ & $42(56.0)$ & \\
\hline Yes & $54(33.5)$ & $21(24.4)$ & $33(44.0)$ & \\
\hline RT duration & & $7.10 \pm 0.77$ & $7.07 \pm 0.84$ & 0.765 \\
\hline Hemoglobin & & $13.95 \pm 1.83$ & $14.09 \pm 1.31$ & 0.570 \\
\hline \multicolumn{5}{|c|}{$\begin{array}{l}\text { CCIS, Charlson Comorbidity Index Score; NUC, nonkeratinizing undifferentiated carcinoma; NDC, } \\
\text { nonkeratinizing differentiated carcinoma; CT, chemotherapy; CCRT, concurrent chemoradiotherapy }\end{array}$} \\
\hline \multicolumn{5}{|c|}{ Values are numbers (percentage) } \\
\hline *Fisher's exac & & & & \\
\hline
\end{tabular}


Table 2

Univariate analyses of risk factors for 3-year LRFS, DMFS, DSS, and OS rates

\begin{tabular}{|c|c|c|c|c|c|c|c|c|}
\hline Variable & $\begin{array}{l}\text { LRFS } \\
(\%)\end{array}$ & $p$ & $\begin{array}{l}\text { DMFS } \\
\text { (\%) }\end{array}$ & $p$ & $\begin{array}{l}\text { DSS } \\
(\%)\end{array}$ & $p$ & $\begin{array}{l}\text { OS } \\
(\%)\end{array}$ & $p$ \\
\hline Age (y) & & 0.482 & & 0.428 & & 0.098 & & 0.151 \\
\hline$<50$ & 92.8 & & 92.2 & & 92.2 & & 87.7 & \\
\hline$\geq 50$ & 90.0 & & 88.1 & & 82.1 & & 79.2 & \\
\hline Sex & & 0.754 & & 0.036 & & 0.213 & & 0.917 \\
\hline Male & 91.0 & & 93.5 & & 89.6 & & 83.4 & \\
\hline Female & 92.3 & & 82.2 & & 81.6 & & 84.1 & \\
\hline Smoke & & 0.490 & & 0.662 & & 0.913 & & 0.940 \\
\hline No & 92.3 & & 89.4 & & 87.3 & & 83.4 & \\
\hline Yes & 89.3 & & 91.7 & & 87.4 & & 83.9 & \\
\hline CCIS & & 0.185 & & 0.229 & & 0.358 & & 0.389 \\
\hline 0 & 92.9 & & 88.8 & & 86.2 & & 82.2 & \\
\hline$\geqq 1$ & 84.9 & & 96.2 & & 92.1 & & 89.7 & \\
\hline T stage & & 0.652 & & 0.035 & & 0.249 & & 0.659 \\
\hline $\mathrm{T} 1 / \mathrm{T} 2$ & 92.8 & & 83.9 & & 83.8 & & 81.9 & \\
\hline T3/T4 & 90.4 & & 94.5 & & 89.7 & & 84.7 & \\
\hline $\mathrm{N}$ stage & & 0.498 & & $<.001$ & & $\begin{array}{l}< \\
0.001\end{array}$ & & 0.006 \\
\hline N0/N1/N2 & 91.8 & & 94.0 & & 90.8 & & 86.5 & \\
\hline N3 & 88.1 & & 63.2 & & 63.2 & & 63.2 & \\
\hline AJCC Stage & & 0.065 & & 0.004 & & 0.002 & & 0.018 \\
\hline Stage 3 & 93.9 & & 94.4 & & 92.3 & & 88.1 & \\
\hline Stage 4 & 84.5 & & 79.6 & & 74.9 & & 72.0 & \\
\hline $\begin{array}{l}\text { Cumulative Cisplatin dose } \\
\left(\mathrm{mg} / \mathrm{m}^{2}\right)\end{array}$ & & 0.795 & & 0.639 & & 0.590 & & 0.557 \\
\hline$<200$ & 91.7 & & 89.1 & & 88.8 & & 85.6 & \\
\hline$\geqq 200$ & 91.0 & & 91.3 & & 85.7 & & 81.4 & \\
\hline
\end{tabular}




\begin{tabular}{|c|c|c|c|c|c|c|c|c|}
\hline Variable & $\begin{array}{l}\text { LRFS } \\
\text { (\%) }\end{array}$ & $p$ & $\begin{array}{l}\text { DMFS } \\
\text { (\%) }\end{array}$ & $p$ & $\begin{array}{l}\text { DSS } \\
\text { (\%) }\end{array}$ & $p$ & $\begin{array}{l}\text { OS } \\
\text { (\%) }\end{array}$ & $p$ \\
\hline Adjuvant CT & & 0.476 & & 0.560 & & 0.461 & & 0.506 \\
\hline No & 90.2 & & 89.2 & & 85.9 & & 82.5 & \\
\hline Yes & 93.4 & & 92.1 & & 89.9 & & 85.9 & \\
\hline
\end{tabular}

After adjusting for other factors, the results remained robust for DMFS and DSS for stage N3 disease ( $p<$ 0.001 , hazard ratio $[\mathrm{HR}]=12.395,95 \%$ confident interval $[\mathrm{Cl}]=3.862-39.777 ; \mathrm{HR}=4.78,95 \% \mathrm{Cl}=1.881-$ 12.151). Female gender $(p=0.045, \mathrm{HR}=2.899,95 \% \mathrm{Cl}=1.026-8.193)$ and stage $\mathrm{T} 1-2$ disease $(\mathrm{HR}=$ $0.290,95 \% \mathrm{Cl}=0.095-0.885$ ) were significantly have a lower DMFS (Table 3). Because of the significant impact of N3 status on survival, patients with a stage N3 disease $(n=21)$ were recruited for the subgroup analysis for CCD (Table 4). For a CCD $\geq 200 \mathrm{mg} / \mathrm{m}^{2}$, we noted higher OS, DSS, DMFS, and LRFS ( $p=$ $0.125, p=0.201, p=0.119$, and $p=0.119$, respectively) (Fig. 1 ). Due to the small sample size, we could only find the survival benefit trends on the stage N3 patients treating with CCD $\geq 200 \mathrm{mg} / \mathrm{m}^{2}$. Compared to stage N3 patients, stage N2 patients had similar OS, DSS, DMFS and LRFS among different CCD (supplementary table 1). 
Table 3

Multivariate analysis for 3-year DMFS, DSS and OS for all patients

\begin{tabular}{|c|c|c|c|c|c|c|c|}
\hline & & DMFS & & DSS & & OS & \\
\hline Variable & Comparison & $p$ & $\begin{array}{l}\mathrm{HR}(95 \% \\
\mathrm{Cl})\end{array}$ & $p$ & $\begin{array}{l}\mathrm{HR} \\
(95 \% \\
\mathrm{Cl})\end{array}$ & $p$ & $\begin{array}{l}\mathrm{HR} \\
(95 \% \\
\mathrm{Cl})\end{array}$ \\
\hline Sex & $\begin{array}{l}\text { Female vs. } \\
\text { Male }\end{array}$ & 0.043 & $\begin{array}{l}2.898 \\
(1.034- \\
8.121)\end{array}$ & & & & \\
\hline T stage & $\begin{array}{l}\text { T3/T4 T3/T4 } \\
\text { vs. T1/T2 }\end{array}$ & 0.080 & $\begin{array}{l}0.385 \\
(0.132- \\
1.122)\end{array}$ & & & & \\
\hline $\mathrm{N}$ stage & $\begin{array}{l}\text { N3 vs. } \\
\text { N0/N1/N2 }\end{array}$ & $<.001$ & $\begin{array}{l}11.555 \\
(3.693- \\
36.156)\end{array}$ & 0.001 & $\begin{array}{l}4.78 \\
(1.881- \\
12.151)\end{array}$ & 0.009 & $\begin{array}{l}3.195 \\
(1.333- \\
7.659)\end{array}$ \\
\hline $\begin{array}{l}\text { Concurrent } \\
\text { Cisplatin } \\
\text { Dose } \\
\left(\mathrm{mg} / \mathrm{m}^{2}\right)\end{array}$ & $\begin{array}{l}\geqq 200 \text { vs. } \\
<200\end{array}$ & & & & & & \\
\hline Adjuvant CT & Yes vs. No & 0.079 & $\begin{array}{l}0.308 \\
(0.083- \\
1.145)\end{array}$ & & & & \\
\hline
\end{tabular}

Table 4

Subgroup analyses of cumulative cisplatin dose on N3 patients $(n=21)$ for 3-year LRFS, DMFS, DSS, and OS rates

\begin{tabular}{|c|c|c|c|c|c|c|c|c|}
\hline Variable & $\begin{array}{l}\text { LRFS } \\
(\%)\end{array}$ & $P$ & $\begin{array}{l}\text { DMFS } \\
(\%)\end{array}$ & $P$ & $\begin{array}{l}\text { DSS } \\
(\%)\end{array}$ & $P$ & $\begin{array}{l}\text { OS } \\
(\%)\end{array}$ & $P$ \\
\hline $\begin{array}{l}\text { Concurrent Cisplatin } \\
\text { dose }\end{array}$ & & 0.125 & & 0.201 & & 0.119 & & 0.119 \\
\hline$<200 \mathrm{mg} / \mathrm{m}^{2}$ & 40.0 & & 40.0 & & 40.0 & & 40.0 & \\
\hline$\geqq 200 \mathrm{mg} / \mathrm{m}^{2}$ & 71.4 & & 71.4 & & 71.4 & & 71.4 & \\
\hline
\end{tabular}

\section{Discussion}

\section{Synopsis of key findings}


We identified that a CCD $\geq 200 \mathrm{mg} / \mathrm{m}^{2}$ might result in better survival outcomes in stage N3 patients. In the entire group of NPC patients, a CCD $\geq 200 \mathrm{mg} / \mathrm{m}^{2}$ or AC did not confer survival benefits. A higher CCD may be exclusively applied for patients with N3 disease to avoid unfavorable toxicity.

\section{Strengths of the study}

The strength of our study was its pure cohort recruitment of only patients with NPC treated with intensitymodulated RT (IMRT). This study is the first investigation of IMRT to identify the specific staged of disease (N3) might benefit from a CCD $\geq 200 \mathrm{mg} / \mathrm{m}^{2}$.

\section{Comparisons with other studies}

Previous studies of CCD cut-off values associated with better survival outcomes have reported inconsistent results.[5,11-16] Some studies have noted superior survival with a CCD $>200 \mathrm{mg} / \mathrm{m}^{2}$, but these investigations used heterogeneous modalities of RT, including two-dimensional RT (2D-RT), threedimensional RT (3D-RT), and IMRT.[5, 11, 12, 14] Lee et al.[5] applied NPC-9901 and NPC-9902 trials and found that the locoregional failure-free rate plateaued (88\%) after a CCD of $200 \mathrm{mg} / \mathrm{m}^{2}$. Wei et al.[11] noted that patients with stage III disease rather than stage IV receiving a CCD $>200 \mathrm{mg} / \mathrm{m}^{2}$ benefitted from longer 5-year progression-free survival and DMFS. Loong et al.[14] showed that a CCD $>200 \mathrm{mg} / \mathrm{m}^{2}$ significantly improved OS in patients with stage II-III disease.

However, IMRT has been shown to yield better OS and LRFS than 2D-RT or 3D-CRT.[17, 18]. In our study that used IMRT, concurrent CT with a CCD $\geq 200 \mathrm{mg} / \mathrm{m}^{2}$ failed to yield better LRFS, DMFS, DSS, or OS outcomes. These findings are consistent with those of another study that used IMRT.[13] Considering the impact on survival of RT modalities in the era of IMRT, the benefit the target group derived from a higher CCD should be investigated further. However, there may be no obvious cut-off CCD value that predicts favorable survival outcomes for treating an entire cohort group of patients with NPC.

In the subgroup analyses, a CCD $\geq 200 \mathrm{mg} / \mathrm{m}^{2}$ resulted in better OS, DSS, DMFS, and LRFS outcomes in patients with stage N3 NPC. Consistent with previous studies that used IMRT, Ou et al.[15] found that a $C C D \geq 300 \mathrm{mg} / \mathrm{m}^{2}$ resulted in superior DMFS and OS in NPC patients with advanced nodal status (N23). Nonetheless, highly diverse treatment arms-including IMRT with or without induction, concurrent CT, or AC-were all included in that study; only $6.5 \%$ patients received CCRT with or without AC. On the other hand, our study specifically focused on patients receiving CCRT with or without AC. Although our finding was not statistically significant due to our small sample size $(n=21)$, our results motivate future investigations enrolling larger cohorts to confirm the survival effect of a larger CCD on patients with regionally advanced NPC.

\section{Weaknesses of the study}

There were some limitations to this study. First and foremost, this retrospective study was conducted at a single institution and included a relatively small number of patients. This made further subgroup analysis by separating patients into intervention and reference cohorts difficult. Furthermore, records of acute side 
effects and late toxicities were incomplete, which prevented us from more thoroughly investigating the association between CCD and adverse effects. We did not routinely measure plasma Ebstein-barr virus DNA level, either. Ebstein-barr virus is known to contribute to the development of nasopharyngeal carcinoma. Last but not least, our study enrolled patients treated with CCRT with or without AC. Therefore, the survival effect of AC may be concerned. Nevertheless, the majority of studies that have reported the efficacy of CCRT with AC compared with CCRT alone failed to demonstrate superior survival outcomes. [19-22]

\section{Conclusions}

N3 status was a clear and independent factor associated with lower DSS and DMFS. A CCD $\geq$ $200 \mathrm{mg} / \mathrm{m}^{2}$ might result in better survival outcomes in stage N3 patients on the basis of OS, DSS, DMFS, and LMFS. In a cohort of patients with NPC receiving CCRT utilizing IMRT with or without AC, there was no statistically significant association between a higher CCD during concurrent CT and survival outcomes. A higher CCD may be exclusively applied in cases of regionally advanced disease to avoid rigorous toxicity.

\section{Abbreviations}

$$
>
$$

NPC, nasopharyngeal carcinoma

RT, radiotherapy

CT, chemotherapy

CCD, cumulative cisplatin dose

CCRT, concurrent chemoradiotherapy

DMFS, distant-metastasis free survival

OS, overall survival

$A C$, adjuvant chemotherapy

LRFS, locoregional-free survival

DSS, disease-specific survival

Gy, Gray

IMRT, intensity-modulated radiotherapy 
2D-RT, two-dimensional radiotherapy

3D-RT, three-dimensional radiotherapy

\section{Declarations}

\section{Ethics approval and consent to participate}

This study was approved by the Institutional Review Board of Kaohsiung Veterans General Hospital, Taiwan (IRB: VGHKS17-CT5-17). The requirement for informed consent was waived because all identifying information was removed from the dataset prior to analysis.

Consent for publication

Not applicable.

Availability of data and material

All data generated or analysed during this study are included in this published article.

\section{Competing interests}

The authors declare that they have no competing interests.

\section{Funding}

None.

\section{Authors' contributions}

Dr. LSC and CTS had full access to all of the data in the study and take responsibility for the integrity of the data and the accuracy of the data analysis. All authors have read and approved the manuscript

Concept and design: LSC, CTS

Acquisition, analysis, or interpretation of data: LSC, LYH, LYS, KBH, CKP, CTS

Drafting the manuscript: LSC, CTS

Critical revision of the manuscript for important intellectual content: LSC, LYH, LYS, KBH, CKP, CTS

Final approval: LSC, LYH, LYS, KBH, CKP, CTS

Acknowledgements

This manuscript is original and it, or any part of it, has not been previously 
published; nor is it under consideration for publication elsewhere.

\section{References}

1. Lam KO, Lee AW, Choi CW, Sze HC, Zietman AL, Hopkins KI, Rosenblatt E. Global Pattern of Nasopharyngeal Cancer: Correlation of Outcome With Access to Radiation Therapy. Int J Radiat Oncol Biol Phys. 2016;94(5):1106-12.

2. Wei KR, Zheng RS, Zhang SW, Liang ZH, Li ZM, Chen WQ. Nasopharyngeal carcinoma incidence and mortality in China, 2013. Chin J Cancer. 2017;36(1):90.

3. Lee AW, Ng WT, Chan LL, Hung WM, Chan CC, Sze HC, Chan OS, Chang AT, Yeung RM. Evolution of treatment for nasopharyngeal cancer-success and setback in the intensity-modulated radiotherapy era. Radiotherapy oncology: journal of the European Society for Therapeutic Radiology Oncology. 2014;110(3):377-84.

4. Al-Sarraf M, LeBlanc M, Giri PG, Fu KK, Cooper J, Vuong T, Forastiere AA, Adams G, Sakr WA, Schuller $\mathrm{DE}$, et al. Chemoradiotherapy versus radiotherapy in patients with advanced nasopharyngeal cancer: phase III randomized Intergroup study 0099. Journal of clinical oncology: official journal of the American Society of Clinical Oncology. 1998;16(4):1310-7.

5. Lee AW, Tung SY, Ngan RK, Chappell R, Chua DT, Lu TX, Siu L, Tan T, Chan LK, Ng WT, et al: Factors contributing to the efficacy of concurrent-adjuvant chemotherapy for locoregionally advanced nasopharyngeal carcinoma: combined analyses of NPC-9901 and NPC-9902 Trials. European journal of cancer (Oxford, England: 1990) 2011, 47(5):656-666.

6. Wang J, Chen YY, Tai A, Chen XL, Huang SM, Yang C, Bao Y, Li NW, Deng XW, Zhao C, et al. Sensorineural Hearing Loss after Combined Intensity Modulated Radiation Therapy and CisplatinBased Chemotherapy for Nasopharyngeal Carcinoma. Translational oncology. 2015;8(6):456-62.

7. Zeng L, Tian YM, Sun XM, Chen CY, Han F, Xiao WW, Deng XW, Lu TX. Late toxicities after intensitymodulated radiotherapy for nasopharyngeal carcinoma: patient and treatment-related risk factors. British journal of cancer. 2014;110(1):49-54.

8. Strojan P, Vermorken JB, Beitler JJ, Saba NF, Haigentz M Jr, Bossi P, Worden FP, Langendijk JA, Eisbruch A, Mendenhall WM, et al. Cumulative cisplatin dose in concurrent chemoradiotherapy for head and neck cancer: A systematic review. Head Neck. 2016;38(Suppl 1):E2151-8.

9. Ang KK. Concurrent radiation chemotherapy for locally advanced head and neck carcinoma: are we addressing burning subjects? Journal of clinical oncology: official journal of the American Society of Clinical Oncology. 2004;22(23):4657-9.

10. Al-Mamgani A, de Ridder M, Navran A, Klop WM, de Boer JP, Tesselaar ME: The impact of cumulative dose of cisplatin on outcome of patients with head and neck squamous cell carcinoma. European archives of oto-rhino-laryngology: official journal of the European Federation of Oto-RhinoLaryngological Societies (EUFOS) : affiliated with the German Society for Oto-Rhino-Laryngology Head and Neck Surgery 2017, 274(10):3757-3765. 
11. Wei W, Huang Z, Li S, Chen H, Zhang G, Li S, Hu W, Xu T. Pretreatment Epstein-Barr virus DNA load and cumulative cisplatin dose intensity affect long-term outcome of nasopharyngeal carcinoma treated with concurrent chemotherapy: experience of an institute in an endemic area. Oncology research treatment. 2014;37(3):88-95.

12. Peng H, Chen L, Zhang Y, Li WF, Mao YP, Zhang F, Guo R, Liu LZ, Lin AH, Sun Y, et al: Prognostic Value of the Cumulative Cisplatin Dose During Concurrent Chemoradiotherapy in Locoregionally Advanced Nasopharyngeal Carcinoma: A Secondary Analysis of a Prospective Phase III Clinical Trial. The oncologist 2016.

13. Guo SS, Tang LQ, Zhang L, Chen QY, Liu LT, Guo L, Mo HY, Luo DH, Huang PY, Xiang YQ, et al. The impact of the cumulative dose of cisplatin during concurrent chemoradiotherapy on the clinical outcomes of patients with advanced-stage nasopharyngeal carcinoma in an era of intensitymodulated radiotherapy. BMC Cancer. 2015;15:977.

14. Loong HH, Ma BB, Leung SF, Mo F, Hui EP, Kam MK, Chan SL, Yu BK, Chan AT. Prognostic significance of the total dose of cisplatin administered during concurrent chemoradiotherapy in patients with locoregionally advanced nasopharyngeal carcinoma. Radiotherapy oncology: journal of the European Society for Therapeutic Radiology Oncology. 2012;104(3):300-4.

15. Ou X, Xu T, He X, Ying H, Hu C. Who benefited most from higher cumulative dose of cisplatin among patients with locally advanced nasopharyngeal carcinoma treated by intensity-modulated radiation therapy? A retrospective study of 527 cases. J Cancer. 2017;8(14):2836-45.

16. Peng H, Chen L, Li WF, Guo R, Mao YP, Zhang Y, Zhang F, Liu LZ, Tian L, Lin AH, et al. The Cumulative Cisplatin Dose Affects the Long-Term Survival Outcomes of Patients with Nasopharyngeal Carcinoma Receiving Concurrent Chemoradiotherapy. Scientific reports. 2016;6:24332.

17. Zhang B, Mo Z, Du W, Wang Y, Liu L, Wei Y. Intensity-modulated radiation therapy versus 2D-RT or 3DCRT for the treatment of nasopharyngeal carcinoma: A systematic review and meta-analysis. Oral Oncol. 2015;51(11):1041-6.

18. Peng G, Wang T, Yang KY, Zhang S, Zhang T, Li Q, Han J, Wu G. A prospective, randomized study comparing outcomes and toxicities of intensity-modulated radiotherapy vs. conventional twodimensional radiotherapy for the treatment of nasopharyngeal carcinoma. Radiotherapy oncology: journal of the European Society for Therapeutic Radiology Oncology. 2012;104(3):286-93.

19. Chen YP, Wang ZX, Chen L, Liu X, Tang LL, Mao YP, Li WF, Lin AH, Sun Y, Ma J. A Bayesian network meta-analysis comparing concurrent chemoradiotherapy followed by adjuvant chemotherapy, concurrent chemoradiotherapy alone and radiotherapy alone in patients with locoregionally advanced nasopharyngeal carcinoma. Annals of oncology: official journal of the European Society for Medical Oncology. 2015;26(1):205-11.

20. Yan M, Kumachev A, Siu LL, Chan KK: Chemoradiotherapy regimens for locoregionally advanced nasopharyngeal carcinoma: A Bayesian network meta-analysis. European journal of cancer (Oxford, England: 1990) 2015, 51(12):1570-1579. 
21. Ribassin-Majed L, Marguet S, Lee AWM, Ng WT, Ma J, Chan ATC, Huang PY, Zhu G, Chua DTT, Chen Y, et al. What Is the Best Treatment of Locally Advanced Nasopharyngeal Carcinoma? An Individual Patient Data Network Meta-Analysis. Journal of clinical oncology: official journal of the American Society of Clinical Oncology. 2017;35(5):498-505.

22. Zhong Q, Zhu X, Li L, Qu S, Liang Z, Zeng F, Pan X. IMRT combined with concurrent chemotherapy plus adjuvant chemotherapy versus IMRT combined with concurrent chemotherapy alone in patients with nasopharyngeal carcinoma. Oncotarget. 2017;8(24):39683-94.

\section{Figures}

(A)

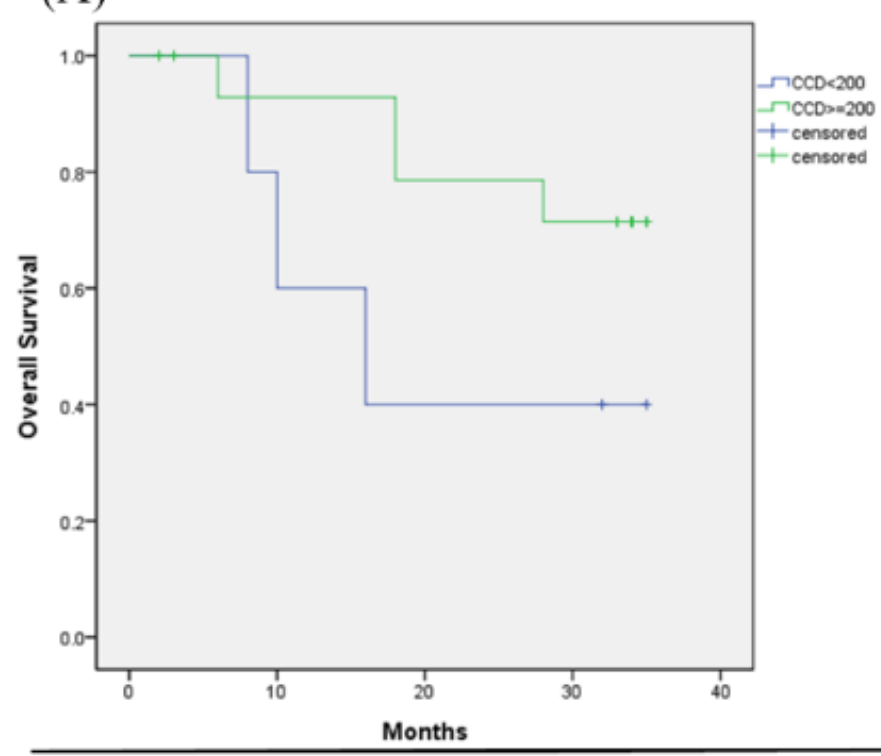

(C)

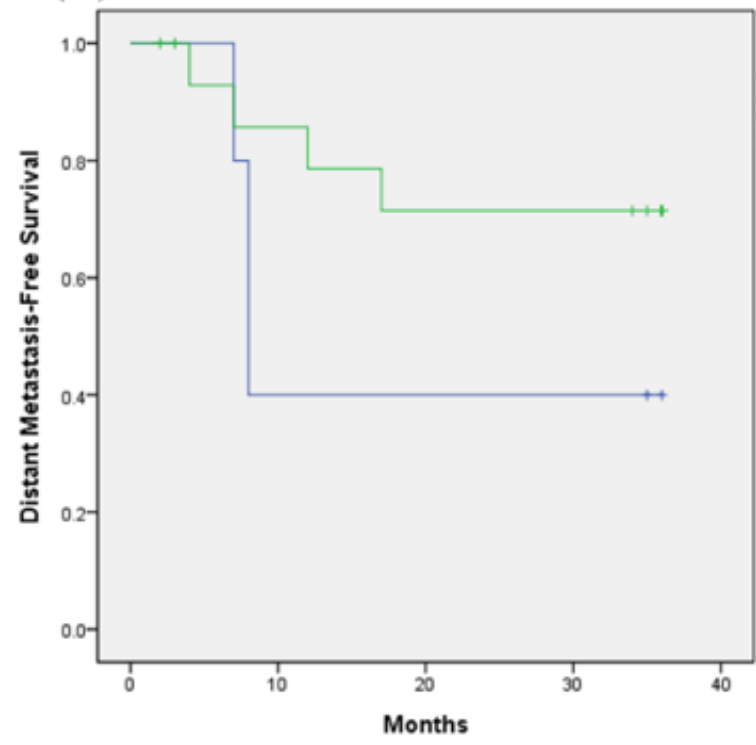

(B)

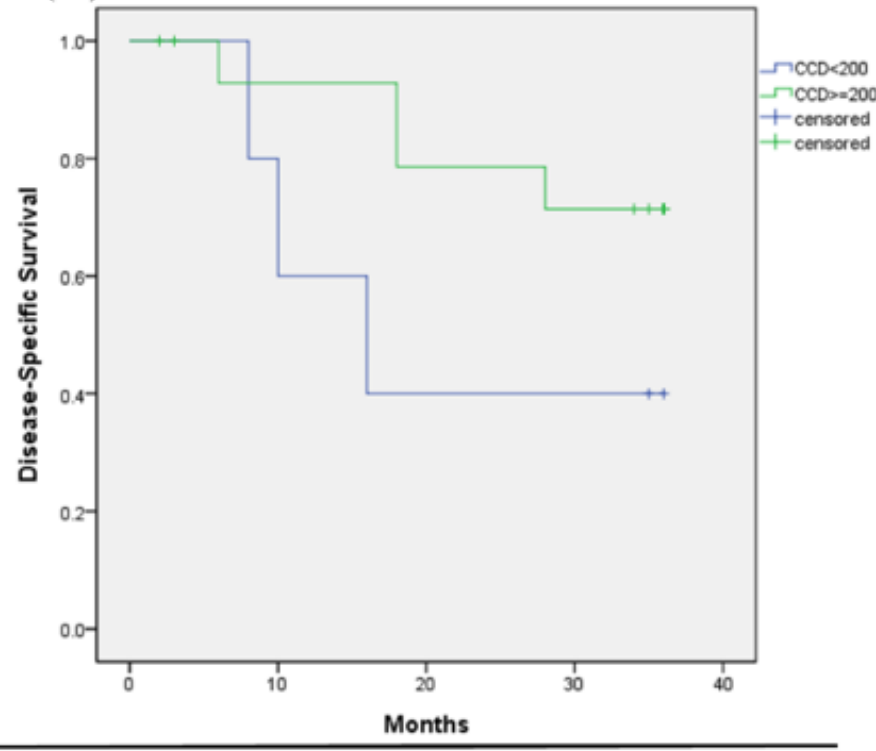

(D)

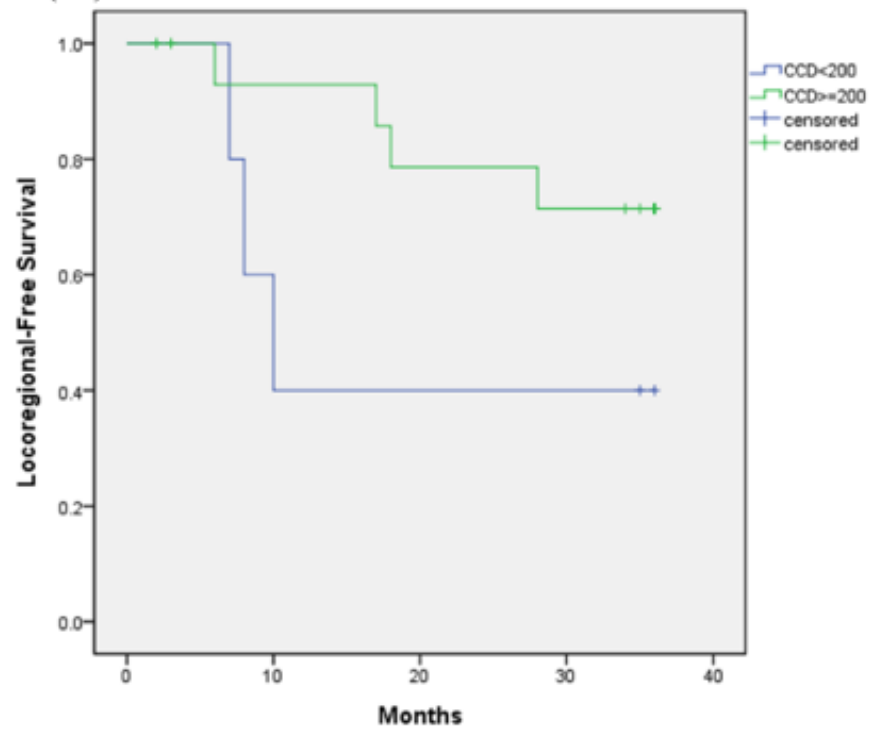

Figure 1 
OS, DSS, DMFS and LRFS for N3 stage patients with high CCD $(\geq 200 \mathrm{mg} / \mathrm{m} 2)$ and low CCD $(<200$ $\mathrm{mg} / \mathrm{m} 2$ ). Patients receiving high CCD have trends toward better (A) 3-year OS ( $p=0.125)$, (B) 3-year DSS $(p=0.201),(C) 3$-year DMFS $(p=0.119)$, and (D) 3-year LRFS $(p=0.119)$

\section{Supplementary Files}

This is a list of supplementary files associated with this preprint. Click to download.

- Supplementarytable120200402.docx 